\title{
Lipid-Lowering Therapy in CKD: Should We Use It and in Which Patients
}

\author{
George A. Kaysen ${ }^{a, b}$ \\ ${ }^{a}$ Department of Medicine, Division of Nephrology, and ${ }^{b}$ Department of Biochemistry and Molecular Medicine, \\ University of California Davis, Davis, CA, USA
}

\section{Key Words}

Low-density lipoprotein · Inflammation · C-reactive protein · High-density lipoprotein · Statins · Fenofibrate

\begin{abstract}
Background: Chronic kidney disease is associated with a 15fold increase in the risk of death and a 30-fold increase in the risk of cardiovascular events even prior to dialysis initiation, and this situation remains unchanged following the initiation of the dialysis procedure. Lipoprotein structure and function, especially the anti-oxidative properties of highdensity lipoprotein, are altered. In this study, the effectiveness of lipid-lowering therapy on mortality and cardiovascular outcomes is explored. Summary: Mortality is inversely associated with the cholesterol level. The degree of inflammation and wasting is a stronger predictor of mortality than are cholesterol levels. Treatment with statins reduces the risk of death and cardiovascular outcomes among patients not yet requiring renal replacement therapy, but is not effective once dialysis is initiated, most likely because other processes, such as inflammation, not affected by lipid-lowering therapy, dominate in the causal pathway leading to adverse outcomes. Fenofibrate is also useful in reducing cardiovascular outcomes and the progression of renal disease among patients with type 2 diabetes not yet requiring dialysis. While
\end{abstract}

the lipid-lowering therapy is effective in patients with the nephrotic syndrome, no long-term outcome studies regarding hard outcomes are available. Key Points: The great increase in cardiovascular outcomes in patients with kidney disease is likely due to a consequence of properties that are unresponsive to the lipid-lowering therapy, most likely inflammation. The lipid-lowering therapy is useful in patients who are not yet in need of dialysis but does not reduce mortality in dialysis patients.

(c) 2017 S. Karger AG, Basel

\section{Background}

The age-standardized risk of death has greatly increased among patients with chronic kidney disease (CKD) even prior to the initiation of dialysis [1]. The primary cause of death is the occurrence of cardiovascular complications [2]. Cardiovascular mortality is increased by as much as 30 times compared to age-based analysis of patients with normal renal function among patients prior to dialysis initiation [1]. These risks of mortality did not reduce once dialysis had been initiated [2]. Dyslipidemia, specifically a low level of high-density lipoprotein (HDL) and increased triglycerides (TGs), and components of the metabolic syndrome are associ-

\section{KARGER}

(C) 2017 S. Karger AG, Basel
George A. Kaysen, MD, PhD

Department of Medicine

University of California Davis, One Shields Ave. Davis

GBSF 451 East Health Sciences Drive, Davis, CA 95616 (USA)

E-Mail gakaysen@ucdavis.edu 
ated with the risk of the development of CKD [3], and alteration, both in lipid levels and structure, leads to metabolic changes that accompany the loss of renal function [4]. HDL maturation is impaired as a consequence of decreased activity of lecithin cholesterol acyl transferase [5], which esterifies cholesterol allowing the expansion of HDL into spherical HDL, an isoform that carries the antioxidant enzymes arylhydrocarbon hydrolase and paraoxinase 1 (PON1) [6]. The lack of maturation results in a disproportionate fraction of residual HDL to remain in the discoid pre $\beta$ subclass, a form that does not bind to PON1 and is an ineffective antioxidant [7]. Thus, HDL in dialysis patients has reduced the ability to protect low-density lipoprotein (LDL) from oxidation [7].

TG-rich lipoproteins, very-LDL (VLDL) and chylomicrons (CM) exhibit a prolonged half-life [8] as a consequence of resistance of the particles to the action of lipoprotein lipase (LPL). This comes as a result of increased concentrations of the LPL inhibitory apolipoproteins C III and apolipoprotein C I relative to the LPL activating apolipoprotein C II. The increased resonance time of VLDL and CM remnant particles further increases their risk of oxidation [4]. The consequence of this is accumulation of increased fraction of LDL that is oxidized [9], although it is uncertain whether oxidized LDL contributes to adverse outcomes in this population [10].

Thus, the levels of lipoproteins in dialysis patients may not provide the same expected effect on outcomes as anticipated based upon effects observed in patients with unimpaired renal function. Indeed, the total cholesterol level $[11,12]$ is inversely associated with mortality in dialysis patients suggesting either that cholesterol may have limited ability to adversely affect outcomes, or that other processes that are not associated with lipid levels have a dominant effect on the observed increase in all-cause and cardiovascular outcomes, perhaps overwhelming the effect mediated by lipoproteins.

\section{Statins}

Several clinical trials exploring the effect of lipid lowering therapy on cardiovascular outcomes and on allcause mortality and morbidity [13-15] have been completed. The $4 \mathrm{D}$ trial was a prospective randomized study of the effect of atorvastatin on cardiovascular mortality, myocardial infarction and stroke in 1,255 dialysis patients with type 2 diabetes [13]. The effect size on primary outcomes, which was a composite of

Lipid-Lowering Therapy in CKD: Should

We Use It and in Which Patients death from cardiac causes, nonfatal myocardial infarction and stroke was small, approximately $13 \%$ and not statistically significant. There was no effect of treatment on inflammation measured as C-reactive protein (CRP). A secondary end point, all cardiac events combined, was significant (RR $0.82(0.68-0.99) ; \mathrm{p}=0.03)$. A second trial examined the effect of rosuvastatin on the primary end point: time to a major cardiovascular event, defined as a nonfatal myocardial infarction, nonfatal stroke, or death from cardiovascular causes. The effect on these outcomes was not significant despite a significant reduction in LDL cholesterol and CRP [14]. The largest study conducted to date is the SHARP study, which evaluated the effect of simvastatin plus ezetimibe on 3,023 dialysis patients and on 6,247 CKD patients who were not on dialysis [15]. The primary outcomes did not include mortality, but were non-fatal myocardial infarction or any cardiac death, any stroke or any arterial revascularization excluding dialysis access procedures. There was a significant reduction in risk by $17 \%$ in the treatment group, but the effect was completely confined to the patients who were not on dialysis. Overall, there was no effect on mortality in the trial (RR $1.02(0.94-1.11)$ ) and no effect on the selected outcomes among dialysis patients (RR 0.90 (0.75-1.08)). Thus, it appears that while treatment with a statin does reduce LDL cholesterol levels and in some instances CRP as well, there is no effect on mortality or on cardiovascular outcomes that are statistically significant among patients on hemodialysis. Conversely, the anticipated effects on cardiovascular outcomes appear to be preserved among patients with CKD who do not yet need renal replacement therapy.

\section{Fibric Acid and Niacin}

Fenofibrate has been observed to increase serum creatinine concentrations in patients with $\mathrm{CKD}$, raising safety concerns [16]. Nevertheless, a randomized controlled trial on the use of fenofibrate in a group of patients with type 2 diabetes and CKD (estimated glomerular filtration rate, eGFR $30-59,60-89$ and $\geq 90 \mathrm{ml} / \mathrm{min} / 1.73 \mathrm{~m}^{2}$ ) showed efficacy (composite of cardiovascular death, myocardial infarction, stroke and coronary/carotid revascularization) that appeared to be confined to the group of patients with eGFR 30-59 [17]. No adverse effect of fenofibrate on renal function was reported. Indeed, despite an initial increase in creatinine, long-term treatment with fenofibrate reduced the rate of loss of renal function 
in patients with type 2 diabetes [18]. It is unclear whether there is therapeutic benefit in the use of fenofibrate in dialysis patients. Use of niacin among dialysis patients has been directed at reduction in serum phosphorous and, with the exception of increased flushing, appears to be safe [19].

\section{Effect of Inflammation}

Although lipid levels and structures among patients requiring dialysis suggest that the lipid-lowering therapy should be effective in this population with a 30 -fold increase in cardiovascular events, reduction in risk is not effected in prospective clinical trials. One explanation for this outcome is that the increased risk acquired as renal function fails is mediated by a process other than the effect of lipids so that any treatment effect is obscured by the acquisition of an additional risk contributor. Inflammation provides such a mechanism [20]. Indeed, in a post hoc analysis of the 4D trial, 'wasting' defined as hypoalbuminemia, low serum creatinine and an elevated CRP resulted in the greatest risk for all-cause mortality and for combined cardiovascular events independently of the cholesterol level [21]. Among dialysis patients, mortality is inversely associated with cholesterol [11], although this association is reversed after adjustment for CRP [12]. A similar disassociation of cholesterol and cardiovascular outcomes in patients with CKD mediated by the presence of inflammation was demonstrated in the African-American Study of Kidney Disease and Hypertension study, where among this cohort of pre dialysis patients with eGFR between 20 and $65 \mathrm{ml} / \mathrm{min} / 1.73 \mathrm{~m}^{2}$, an increasing hazards ratio for cardiovascular outcomes was observed among the patients without inflammation, while this relationship was obscured among patients with inflammation [22]. Thus, the acquisition of a cardiovascular and mortality risk factor that is independent of lipid levels and most likely contributing to significantly more risk for adverse outcomes would tend to obscure any potential benefit of the lipid-lowering therapy.

\section{Lipid-Lowering Therapy in the Nephrotic Syndrome}

The nephrotic syndrome is associated with significant increases in blood lipid levels as a consequence of proteinuria [23]. Hyperlipidemia can be reduced by decreasing urinary albumin loss [24] and is a consequence of increased synthesis of LDL, lipoprotein (a) $[25,26]$ and decreased lipolysis of TG-rich lipoproteins as a consequence of retention of fatty acid enriched albumin by selective sieving by damaged podocytes, which in turn stimulates the production of circulating angiopoeitin-like 4 protein [27], an inhibitor of LPL.

Statins are effective in reducing lipid levels in nephrotic patients [28], but no long-term hard outcome studies are available to access treatment effects. In addition to increased LDL synthesis, defective removal as a consequence of increased levels of proprotein convertase subtilisin/kexin type 9 has been described to be increased as a consequence of increased hepatic synthesis. Inhibition of this protein presents another potential therapeutic target for control of hyperlipidemia in this syndrome [29].

\section{Acknowledgement}

The author received funding from NIDDK and DCI.

\section{Disclosure Statement}

The author declares no conflicts of interest.

\section{References}

1 Go AS, Chertow GM, Fan D, McCulloch CE, Hsu CY: Chronic kidney disease and the risks of death, cardiovascular events, and hospitalization. N Engl J Med 2004;351: 1296-1305.

2 USRDS 17th Annual report NIH/NIDDK/ Division of Kidney, Urologic and Hematologic Diseases Annual, 2005, pp 128-129.

3 Guarnieri G, Zanetti M, Vinci P, Cattin MR, Pirulli A, Barazzoni R: Metabolic syndrome and chronic kidney disease. J Ren Nutr 2010; 20(5 suppl):S19-S23.
4 Ananthakrishnan S, Kaysen GA: Treatment of hyperlipidemia changes with level of kidney function-rationale. Adv Chronic Kidney Dis 2016;23:247-254.

5 Miida T, Miyazaki O, Hanyu O, et al: LCATdependent conversion of prebeta1-HDL into alpha-migrating HDL is severely delayed in hemodialysis patients. J Am Soc Nephrol 2003; 14:732-738.

6 Mahrooz A, Zargari M, Sedighi O, Shaygani $\mathrm{H}$, Gohari G Increased oxidized-LDL levels and arylesterase activity/HDL ratio in ESRD patients treated with hemodialysis. Clin Invest Med 2012;35:E144-E151.

7 Morena M, Cristol JP, Dantoine T, Carbonneau MA, Descomps B, Canaud B: Protective effects of high-density lipoprotein against oxidative stress are impaired in haemodialysis patients. Nephrol Dial Transplant 2000;15:389-395.

8 Lee DM, Knight-Gibson C, Samuelsson O, Attman PO, Wang CS, Alaupovic P: Lipoprotein particle abnormalities and the impaired lipolysis in renal insufficiency. Kidney Int 2002;61:209-218. 
9 Ribeiro S, Faria Mdo S, Silva G, Nascimento $\mathrm{H}$, Rocha-Pereira P, Miranda V, Vieira E, Santos R, Mendonça D, Quintanilha A, Costa E, Belo L, Santos-Silva A: Oxidized low-density lipoprotein and lipoprotein(a) levels in chronic kidney disease patients under hemodialysis: influence of adiponectin and of a polymorphism in the apolipoprotein(a) gene. Hemodial Int 2012;16:481-490.

10 Sevinc Ok E, Kircelli F, Asci G, Altunel E, Ertilav M, Sipahi S, Bozkurt D, Duman S, Ozkahya M, Toz H, Ok E: Neither oxidized nor anti-oxidized low-density lipoprotein level is associated with atherosclerosis or mortality in hemodialysis patients. Hemodial Int 2012;16: 334-341.

11 Lowrie EG, Lew NL: Death risk in hemodialysis patients: the predictive value of commonly measured variables and an evaluation of death rate differences between facilities. Am J Kidney Dis 1990;15:458-482.

12 Liu Y, Coresh J, Eustace JA, Longenecker JC, Jaar B, Fink NE, Tracy RP, Powe NR, Klag MJ: Association between cholesterol level and mortality in dialysis patients: role of inflammation and malnutrition. JAMA 2004;291:451-459.

13 Wanner C, Krane V, März W, Olschewski M, Mann JF, Ruf G, Ritz E; German Diabetes and Dialysis Study Investigators: Atorvastatin in patients with type 2 diabetes mellitus undergoing hemodialysis. N Engl J Med 2005;353: 238-248; erratum in N Engl J Med 2005;353: 1640.

14 Fellström BC, Jardine AG, Schmieder RE, Holdaas H, Bannister K, Beutler J, Chae DW, Chevaile A, Cobbe SM, Grönhagen-Riska C, De Lima JJ, Lins R, Mayer G, McMahon AW, Parving HH, Remuzzi G, Samuelsson O, Sonkodi S, Sci D, Süleymanlar G, Tsakiris D, Tesar V, Todorov V, Wiecek A, Wüthrich RP, Gottlow M, Johnsson E, Zannad F; AURORA Study Group: Rosuvastatin and cardiovascular events in patients undergoing hemodialysis. N Engl J Med 2009;360:1395-1407; erratum in N Engl J Med 2010;362:1450.
15 Baigent C, Landray MJ, Reith C, Emberson J, Wheeler DC, et al: The effects of lowering LDL cholesterol with simvastatin plus ezetimibe in patients with chronic kidney disease (Study of Heart and Renal Protection): a randomised placebo-controlled trial. Lancet 2011;377:2181-2192.

16 McPherson R, Frohlich J, Fodor G, Genest J; Canadian Cardiovascular Society: Canadian Cardiovascular Society position statement recommendations for the diagnosis and treatment of dyslipidemia and prevention of cardiovascular disease. Can J Cardiol 2006;22: 913-927.

17 Ting RD, Keech AC, Drury PL, Donoghoe MW, Hedley J, Jenkins AJ, Davis TM, Lehto S, Celermajer D, Simes RJ, Rajamani K, Stanton K; FIELD Study Investigators: Benefits and safety of long-term fenofibrate therapy in people with type 2 diabetes and renal impairment: the FIELD study. Diabetes Care 2012; 35:218-225

18 Davis TM, Ting R, Best JD, Donoghoe MW, Drury PL, Sullivan DR, Jenkins AJ, O'Connell RL, Whiting MJ, Glasziou PP, Simes RJ, Kesäniemi YA, Gebski VJ, Scott RS, Keech AC; Fenofibrate Intervention and Event Lowering in Diabetes Study Investigators: Effects of fenofibrate on renal function in patients with type 2 diabetes mellitus: the Fenofibrate Intervention and Event Lowering in Diabetes (FIELD) study. Diabetologia 2011;54:280290.

19 He YM, Feng L, Huo DM, Yang ZH, Liao YH: Benefits and harm of niacin and its analog for renal dialysis patients: a systematic review and meta-analysis. Int Urol Nephrol 2014;46: 433-442.

20 Yeun JY, Levine RA, Mantadilok V, Kaysen GA: C-reactive protein predicts all-cause and cardiovascular mortality in hemodialysis patients. Am J Kidney Dis 2000;35:469-476.

21 Drechsler C, Grootendorst DC, Pilz S, Tomaschitz A, Krane V, Dekker F, März W, Ritz E, Wanner C: Wasting and sudden cardiac death in hemodialysis patients: a post hoc analysis of 4D (Die Deutsche Diabetes Dialyse Studie). Am J Kidney Dis 2011;58:599-607.

22 Contreras G, Hu B, Astor BC, et al: Malnutrition-inflammation modifies the relationship of cholesterol with cardiovascular disease. J Am Soc Nephrol 2010;21:2131-2142.

23 Davies RW, Staprans I, Hutchison FN, Kaysen GA: Proteinuria, not altered albumin metabolism, affects hyperlipidemia in the nephrotic rat. J Clin Invest 1990;86:600605.

24 Kaysen GA, Davies RW: Reduction in proteinuria attenuates hyperlipidemia in the nephrotic syndrome. J Am Soc Nephrol 1990; 1(5 suppl 2):S75-S79.

25 De Sain-Van Der Velden MG, Reijngoud DJ, Kaysen GA, Gadellaa MM, Voorbij H, Stellaard F, Koomans HA, Rabelink TJ: Evidence for increased synthesis of lipoprotein(a) in the nephrotic syndrome. J Am Soc Nephrol 1998; 9:1474-1481.

26 de Sain-van der Velden MG, Kaysen GA, Barrett HA, Stellaard F, Gadellaa MM, Voorbij HA, Reijngoud DJ, Rabelink TJ: Increased VLDL in nephrotic patients results from a decreased catabolism while increased LDL results from increased synthesis. Kidney Int 1998;53:994-1001.

27 Clement LC, Macé C, Avila-Casado C, Joles JA, Kersten S, Chugh SS: Circulating angiopoietin-like 4 links proteinuria with hypertriglyceridemia in nephrotic syndrome. Nat Med 2014;20:37-46.

28 Kong X, Yuan H, Fan J, Li Z, Wu T, Jiang L: Lipid-lowering agents for nephrotic syndrome. Cochrane Database Syst Rev 2013; 12:CD005425.

29 Haas ME, Levenson AE, Sun X, Liao WH, Rutkowski JM, de Ferranti SD, Schumacher VA, Scherer PE, Salant DJ, Biddinger SB: The role of proprotein convertase subtilisin/Kexin type 9 in nephrotic syndrome-associated hypercholesterolemia. Circulation 2016;134: 61-72. 